\title{
ECOSYSTEM FOR HEALTHCARE SERVICES AND MANAGEMENT SYSTEM
}

\author{
Azana Hafizah Mohd Aman \\ Senior Lecturer, Faculty of \\ Information Science and Technology, \\ National University of Malaysia. \\ Selangor (Malaysia). \\ E-mail: azana@ukm.edu.my
}

Syed Abdul Mutalib Al Junid Senior Lecturer, Faculty of Electrical Engineering, Universiti Teknologi MARA, Shah Alam, Selangor (Malaysia).

E-mail:samaljunid@uitm.edu.my

\section{Hasimi Salehudin}

Senior Lecturer, Faculty of Information Science and Technology, National University of Malaysia. Selangor (Malaysia). E-mail: hasimi@ukm.edu.my
Adil Hidayat

Director, My6 Initiative Berhad. Cyberjaya

(Malaysia).

E-mail: adil@my6.my

Rosilah Hassan

Associate Professor, Faculty of Information Science and Technology, National University of Malaysia. Selangor (Malaysia). E-mail:rosilah@ukm.edu.my

\section{Syed Mohamed Aljunid}

Professor, Faculty of Medicine, National University of Malaysia. Kuala Lumpur

(Malaysia).

Faculty of Public Health, Dept of Health Policy and Management, Kuwait University (Kuwait). E-mail: smohamed@ppukm.ukm.edu.my

Recepción: 29/07/2019 Aceptación: 19/09/2019 Publicación: 06/11/2019

\section{Gitación sugerida:}

Aman, A.H.M., Al Junid, S.A.M., Salehudin, H., Hidayat, A., Hassan, R. y Aljunid, S.M. (2019). Ecosystem for healthcare services and management system. 3C Tecnología. Glosas de innovación aplicadas a la pyme. Edición Especial, Noviembre 2019, 121-131. doi: http:/ / dx.doi.org/10.17993/3ctecno.2019.specialissue3.121-131

\section{Suggested citation:}

Aman, A.H.M., Al Junid, S.A.M., Salehudin, H., Hidayat, A., Hassan, R. \& Aljunid, S.M. (2019). Ecosystem for healthcare services and management system. $3 C$ Tecnología. Glosas de innovación aplicadas a la pyme. Speciaal Issue, November 2019, 121-131. doi: http:/ / dx.doi.org/10.17993/3ctecno.2019.specialissue3.121-131 


\section{ABSTRACT}

Dengue fever is one of the neglected tropical diseases (NTDs) in the Southeast Asian Countries (ASEAN), almost 70 million cases of dengue fever occur annually. This infection is now one of the most economically important NTDs in the region. Hence, there are urgent needs to spread public awareness on NTDs, the prevention, the treatment and the clinical cost involved. An innovation in health services and management system is needed to cater this issue. Intelligent Ecosystem for Healthcare Service and Management (IEHSM) is an integration of healthcare management, health knowledge base and data reference, control and elimination tools, and clinical costing. The main objective of this research is to provide a model for the improvement of fundamental understanding of public health especially NTDs and at the same time improve the existing healthcare services and management system. IEHSM adapts the optimization of prevention emphasizing on therapeutic approaches through Big Data Analytics, Artificial Intelligent, Cloud Computing, Machine Learning and Information Centric Networking. The IEHSM framework is based on Casemix system, a system that aggregates information about patients and associated procedures based on the type and mix of patients' treatment.

\section{KEYWORDS}

Intelligent Healthcare Ecosystem, Artificial Intelligence, Cloud Computing, Big Data. 


\section{INTRODUCTION}

The Southeast Asian Countries (ASEAN) are still facing issues of neglected tropical diseases (NTDs). Nearly 650 million people live in ASEAN countries, about 200 million come from the low or lower middle-income countries and many of them are affected by at least one NTD (World Health Organization, 2019). However, NTDs also affect upper middle-income ASEAN countries such as Malaysia. In Malaysia as reported by World Health Organization (WHO), during week 26, 2019 , a total of 2,806 dengue cases including one death was reported, bringing the cumulative number as of 29 June 2019 to 62,421 cases including 93 deaths. This is higher compared to 32,425 cases with 53 deaths reported during the same period last year (World Health Organization, 2019). Weakness in public awareness and understanding, shows that the health systems need to be improved. An urgency to effectively spread public awareness on NTDs prevention (Asat, 2018), treatment and clinical cost (Ibrahim, 2019) involved. Obviously current health services are unable to attract the public interest and awareness, despite having heterogenous technology and excellent infrastructure, these services are not interesting, not approachable or not user friendly to the public.

Intelligent Ecosystem for Healthcare Service and Management (IEHSM) is an integration of healthcare management (doctors, medical experts and patients), health knowledge base and data reference, control and elimination tools, and clinical costing. One of the goals of this research is to help the public by educating them about their medical status and keeping them health-aware as the saying goes 'prevention is better than cure'. The main objective of this research is to provide a model for the improvement of fundamental understanding of public health especially NTDs and at the same time improve the existing healthcare services and management system. IEHSM also empowers public to self-manage information, an emphasis on improving the quality of interesting and deliverable health awareness information. IEHSM helps in utilizing available current health system resources to their maximum potential. It also aids remote monitoring of patients and helps in reducing the cost of treatment via medical practitioners' support that extend their services without any geographical barriers. 
IEHSM adapts the optimization of prevention emphasizing on therapeutic approaches through Big Data Analytics (Wikipedia, 2019), Artificial Intelligent (AI) (Wikipedia, 2019), Machine Learning (Wikipedia, 2019), Cloud Computing (Wikipedia, 2019) and Information Centric Networking (ICN) (Aman, 2019). Machine learning is the scientific study of algorithms and statistical models that computer systems use in order to perform a specific task effectively without using explicit instructions, relying on patterns and inference instead. It is seen as a subset of artificial intelligence. In computer science, artificial intelligence, sometimes called machine intelligence, is intelligence demonstrated by machines, in contrast to the natural intelligence displayed by humans. While Big data is a field that treats ways to analyze, systematically extract information from, or otherwise deal with data sets that are too large or complex to be dealt with by traditional data-processing application. Cloud computing (Al Junid et al., 2012) is the on-demand availability of computer system resources, especially data storage and computing power that is available to many users over the Internet. Information Centric Networking is an approach to evolve the current Internet infrastructure to content based distribution. It is hoped that, with the integration of these technologies the new proposed IEHSM will help to produce better healthcare ecosystem.

\section{RESEARCH METHODOLOGY}

The IEHSM framework is based on Casemix system (Casemix, 2019), a health system that aggregates information about patients and associated procedures based on the type and mix of patients' treatment. The current Casemix grouper uses International Classification of Disease, Tenth Revision (ICD-10), as for this research ICD-10 will be upgraded, modified and improved based on the new IEHSM model. The first stage of the research methodology will involve investigation of research problem followed by framework design stage and finally validation of the proposed model. The details of the stages are explained in Table 1. 
Table 1. Methodology Stages.

\begin{tabular}{|c|c|c|}
\hline Stages & $\begin{array}{c}\text { Description } \\
\text { Sroblems, solutions and methodology identification phase. The target } \\
\text { scopes are NTDs, Casemix, IEHSM, Therapeutic approaches, Big Data } \\
\text { Analytics, Artificial Intelligent, Machine Learning, Cloud Computing and } \\
\text { Information Centric Networking. Hence this phase focuses on identifying } \\
\text { research problems and research gap for NTDs and Casemix system } \\
\text { Stage 1 } \\
\text { environment. Also, to find the possible solutions and methodology offered by } \\
\text { Big Data Analytics, Artificial Intelligent, Machine Learning, Cloud Computing } \\
\text { and Information Centric Networking that satisfies the improvement of public } \\
\text { health especially NDTs. Additionally, other critical system information and } \\
\text { system parameters that affect the functionality of the IEHSM system will also } \\
\text { be identified. }\end{array}$ \\
\hline Stage 2 & $\begin{array}{c}\text { Framework design and implementation phase. This phase focuses on how to } \\
\text { initialize solution and satisfy the information requirement to develop IEHSM } \\
\text { environment. In order to accomplish this goal, by using stage 1 results the } \\
\text { baseline model for the proposed IEHSM will be logically drawn. Based on } \\
\text { the baseline design, the pseudo code/flowchart, communication process, } \\
\text { mathematical models and algorithm will then be developed. }\end{array}$ \\
\hline Stage 3 & $\begin{array}{r}\text { Evaluation and results analysis phase. The proposed IEHSM will be } \\
\text { analyzed through user acceptance test. The performance will be evaluated } \\
\text { and benchmark with existing system. }\end{array}$ \\
\hline
\end{tabular}

This research will produce preliminary analysis for IEHSM in order to adapt new ICD-11 and therapeutic prevention approaches. As per above research background, the following research questions and objectives mapping are formulated and presented in Table 2.

Table 2. Research Questions and Objectives.

\section{Research Questions}

How to intelligently adapt prevention approaches in IEHSM?

How to employ Big Data Analytics, Artificial Intelligent, Machine Learning, Cloud Computing and Information Centric

Networking for an effective IEHSM environment?

How to efficiently provide approachable, interesting, deliverable and public friendly IEHSM system?

\section{Research Objectives}

To intelligently adapt prevention approaches in IEHSM

To employ Big Data Analytics, Artificial Intelligent, Machine Learning and Cloud

Computing for an effective IEHSM environment.

To efficiently provide approachable, interesting, deliverable and public friendly IEHSM system. 


\section{PRELIMINARY ANALYSIS}

Casemix is one of the available health systems in ASEAN. Currently Casemix system solutions consist of Grouper, DataTool, Code Assist, Clinical Cost, Casemix Cloud and Casemix Hospital Information System (HIS). Grouper (Aljunid et al., 2011) is a universal and unified patient grouping to convert diagnosis and procedures done by clinician into a single Casemix code called UNU-CBG. While the DataTool assigns diagnosis and procedure codes, it simplifies the coding process and help to improve coding quality. Clinical Cost Modeling consists of CGM module, Casemix Module, and Hospital Tariff module. CGM module is used to calculate cost per patient per stay by ward and cost per patient per visit by clinic. Meanwhile, Casemix module is used to impute cost per UNU-CBG group. Lastly, Hospital Tariff module is used to calculate the UNU-CBG group tariff per patient. Casemix is also accessible via web based in cloud computing. Casemix has a centralized Hospital Information System (HIS). Casemix systems are shown in Graphic 1, Graphic 2, Graphic 3 and Graphic 4.

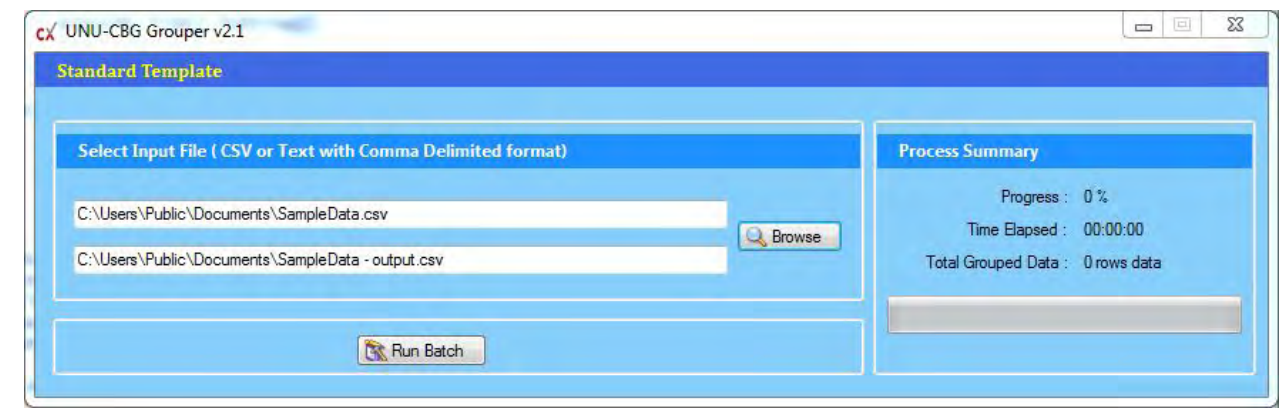

Graphic 1. Grouper. Source: (Casemix Solutions, 2019). 
Edición Especial Special Issue Noviembre 2019 DOI: http://dx.doi.org/10.17993/3ctecno.2019.specialissue3.121-131

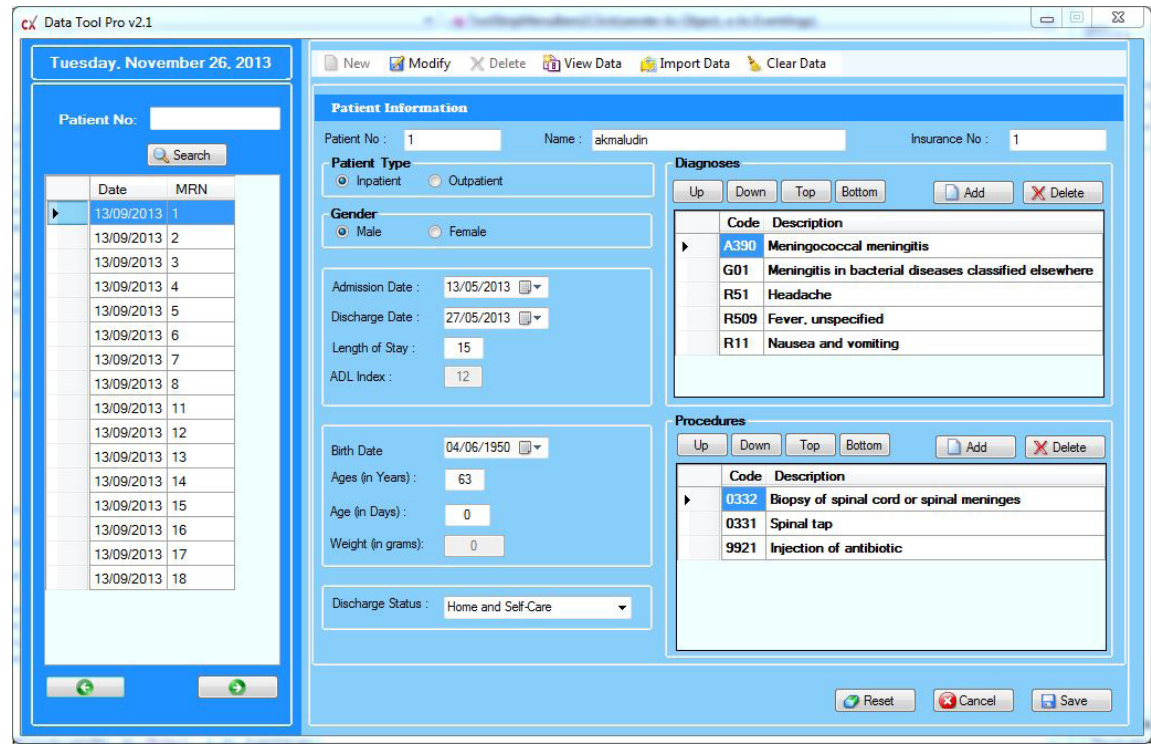

Graphic 2. Data Tool. Source: (Casemix Solutions, 2019).

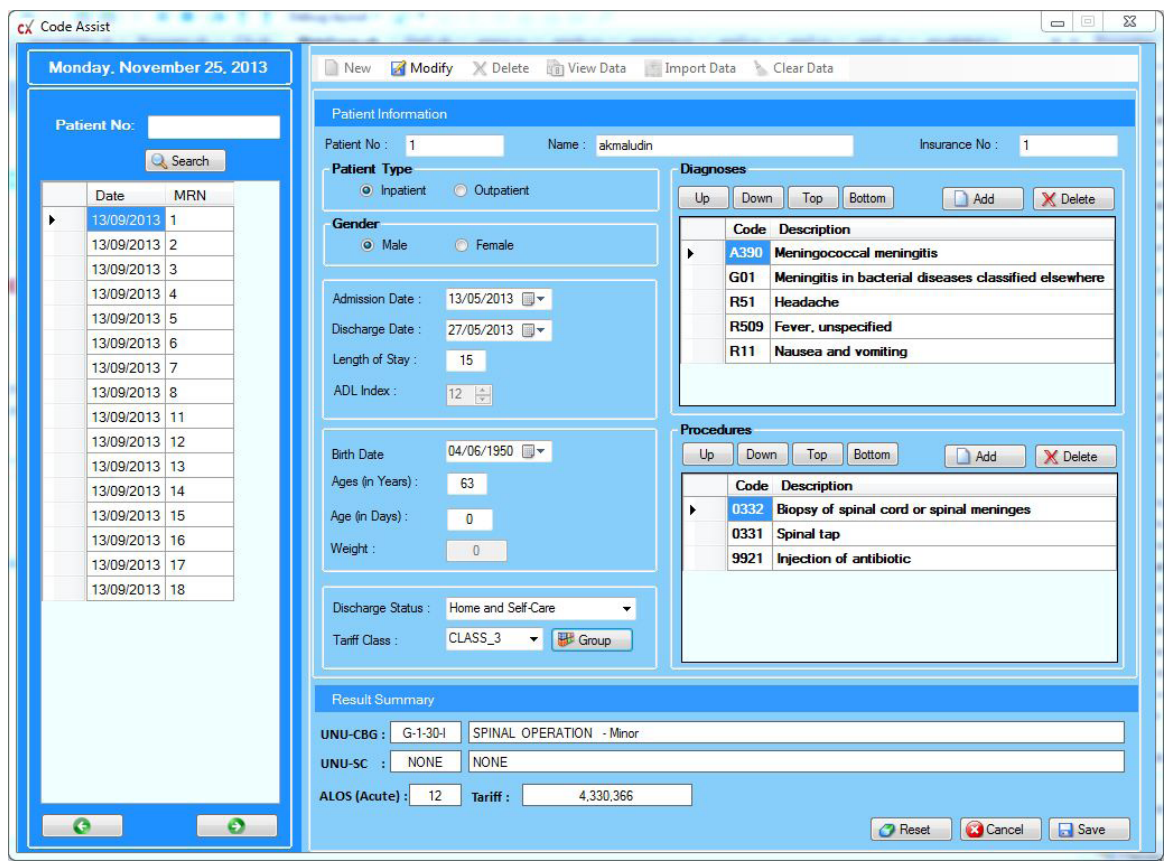

Graphic 3. Code Assist. Source: (Casemix Solutions, 2019). 


\section{Clinical Cost Modelling}
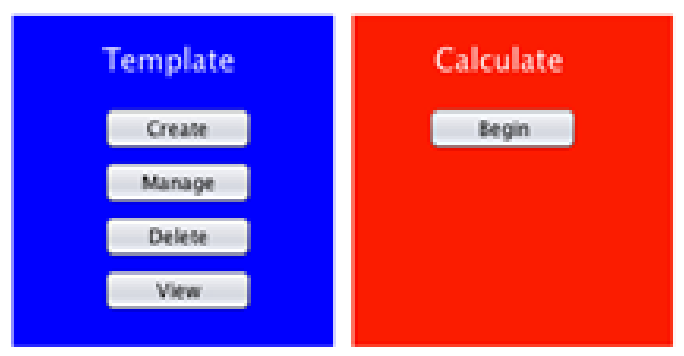

Graphic 4. Clinical Cost. Source: (Casemix Solutions, 2019).

Despite all these solutions Casemix still needs to be improved and upgraded for future changes in diagnosis and procedure classifications as well as features such as prevention of NTDs using therapeutic approaches. An innovation in health services and management to improve health system deliverable and efficient public health awareness system is highly needed. Table 3 shows the preliminary analysis between casemix and IEHSM.

Table 3. Preliminary Analysis.

\begin{tabular}{|c|c|c|}
\hline Parameter & Casemix & IEHSM \\
\hline Healthcare management & Yes & Yes \\
\hline Clinical costing & Yes & Yes \\
\hline Prevention approaches & No & Yes \\
\hline Health knowledge base & Yes & Yes \\
\hline Interactive communication & No & Yes \\
\hline Public friendly & No & Yes \\
\hline Smart technologies & Cloud Computing & $\begin{array}{r}\text { Big Data, Al, Machine } \\
\text { Learning, Cloud Computing } \\
\text { and ICN. }\end{array}$ \\
\hline
\end{tabular}




\section{ACKNOWLEDGEMENT}

The authors are grateful to Faculty of Information Science and Technology, National University of Malaysia. This research is also funded by research grant DIP-2018040 .

\section{CONCLUSIONS}

IEHSM preliminary analysis based on Casemix framework is necessary in order to knows the enhancement needed. It is the initial stage of the IEHSM development phase. As for future work, investigation will be done for other scope areas which are NTDs, Therapeutic approaches, Big Data Analytics, Artificial Intelligent, Machine Learning, Cloud Computing and Information Centric Networking. It is hoped that the completed research will empower smart and intelligent health services and management system to be sustainable globally and greater public health engagement.

\section{REFERENCES}

Al Junid, S. A. M., Aljunid, S., Sulong, S., Hamzah, S. M., Nur, A. M., \& Mustafa, H. R. (2012). Cloud Computing: Feasibility of Developing Webbasd UNU Casemix Grouper. IEEE Business, Engineering \& Industrial Applications Colloquium (BELAC). doi: https://doi.org/10.1109/BEIAC.2012.6226092

Aljunid, S. M., Hamzah, S. M., Mutalib, S. A., Nur, A. M., Shafie, N., \& Sulong, S. (2011). The UNU-CBGs: development and deployment of a real international open source Casemix grouper for resource challenged countries. BMC Health Services Research, 11(Suppl. 1). doi: https://doi.org/10.1186/14726963-11-S1-A4

Aman, A. H. M., Hassan, R., Hashim, A. H. A., \& Ramli, H. A. M. (2019). Investigation of Internet of Things Handover Process for Information Centric Networking and Proxy Mobile Internet Protocol. 3rd International Multi-Topic Conference on Engineering and Science, 2019. 
Artificial Intelligence. (2019). Wikipedia. Retrieved from: https://en.wikipedia. org/wiki/Artificial_intelligence

Asat, A. N., Mahat, A. F., Hassan, R. \& Ahmed, A. S. (2018). Development of dengue detection and prevention system (Deng-E) based upon open data in Malaysia. Proceedings of the 2017 6th International Conference on Electrical Engineering and Informatics: Sustainable Society Through Digital Innovation, ICEEI 2017. Institute of Electrical and Electronics Engineers Inc. Retrieved from: https://ukm. pure.elsevier.com/en/publications/development-of-dengue-detection-andprevention-system-deng-e-base

Big Data. (2019). Wikipedia. Retrieved from: https://en.wikipedia.org/wiki/Big data

Casemix Solutions. (2019). Retrieved from: http://www.casemix.com.my/web/

Gloud Computing. (2019). Wikipedia. Retrieved from: https://en.wikipedia.org/ wiki/Cloud_computing

Ibrahim, R., Aman, A.H.M., Nur, A.M., \& Aljunid, S.M. (2019). Cost Centric Data Mining for Radiology Procedures at Teaching Hospital in Malaysia. 3rd International Multi-Topic Conference on Engineering and Science, 2019.

Information Gentric Networking. (2019). Wikipedia. Retrieved from: https:// en.wikipedia.org/wiki/Information-centric_networking

Machine Learning. (2019). Wikipedia. Retrieved from: https://en.wikipedia.org/ wiki/Machine_learning

World Health Organization. (2019). Retrieved from: https://www.who.int/ 
Edición Especial Special Issue Noviembre 2019

DOI: http://dx.doi.org/10.17993/3ctecno.2019.specialissue3.121-131 